\title{
Pyridoxal Phosphate a Possible Intervention to Prevent Aminoglycoside Induced Electrolyte Imbalance
}

\author{
Afzal H. Asif ${ }^{1}$, Sahibzada T. Rasool ${ }^{2}$ and Tahir M Khan ${ }^{1 *}$ \\ ${ }^{1}$ Department of Pharmacy Practice, College of Clinical Pharmacy, King Faisal University, Kingdom Of Saudi Arabia \\ ${ }^{2}$ Department of Basic Medical Science, College of Clinical Pharmacy, King Faisal University, Kingdom Of Saudi Arabia
}

\begin{abstract}
Aminoglycosides are very effective against most Gram negative infections, but nephrotoxicity and electrolyte imbalance caused by these compounds pose problems in patients where electrolyte balance needs to be watched closely. The electrolyte imbalance contributes to derangement of the renal functions. This issue has been addressed by changing the dosing schedule and supplementing the patients with these electrolytes. However electrolyte administration and adjusting aminoglycoside doses have their own demerits. In our present study we investigated the effects of Pyridoxal phosphate on electrolyte balance when given in combination with aminoglycosides. Our findings suggest that Pyridoxal phosphate prevents aminoglycoside induced electrolyte imbalance, a finding which has not been reported previously. These results should be considered as an important input regarding prevention of aminoglycoside induced decrease in electrolyte levels. Further studies will help healthcare providers to manage patients more efficiently, in whom electrolytes balance may need to be observed.
\end{abstract}

\section{Introduction}

Recently many of the Gram-negative infections have resurfaced which revived the interest of physicians in the use of aminoglycosides. However this has brought back to light the issues related to these drugs i.e. the spectrum of antimicrobial susceptibility and their toxicity [1]. Antimicrobial effect of aminoglycosides is concentration dependent and increases with increasing concentrations of the antibiotic [2]. The killing effect of the aminoglycosides persist even after the medicine has been discontinued [3]. Dose dependent bactericidal effect and postantibiotic effect make aminoglycosides a good candidate for once-daily dosing in patients with normal renal function and since the dosing intervals are longer, toxicity may also be reduced $[4,5]$. Nephrotoxicity is a common side effect of the aminoglycosides [6]. Albeit once-daily regimen has improved the state of affairs over what prevailed thirty years ago, the safety of aminoglycosides remains a controversial issue as far as renal tissue is concerned $[7,8]$.

Among other aberrations aminoglycosides decrease the serum levels of various electrolytes like calcium, potassium and magnesium, a phenomenon which is attributed to tubular injury caused by these drugs [9]. Hypocalcaemia has been reported in the patients who were treated with Aminoglycosides [10-12]. To prevent hypocalcaemia, calcium may be added in diet which may reduce the nephrotoxic potential of the drug, but it does not reduce drug accumulation in the renal cortex [13]. Renal potassium depletion has been ascribed to depression of $\mathrm{Na}^{+}-\mathrm{K}^{+}$-ATPase and decreased serum potassium levels in turn augment the toxic effects of aminoglycosides [14,15]. Hence potassium may be supplemented to avoid its deficiency, especially in patients at risk of acute renal failure, but a falling glomerular filtration rate in the presence of potassium load could result in potentially serious hyperkalemia [16].

Pyridoxal phosphate has nephroprotective effects against various aminoglycosides $[17,18]$. The electrolyte imbalance contributes to derangement of the renal functions. This issue has been addressed by changing the dosing schedule and supplementing the patients with these electrolytes. However adjusting the proper dose and span of electrolyte administration do pose problems $[13,16]$. In our present study we investigated the effects of Pyridoxal phosphate on potassium and calcium serum levels when given in combination with Gentamycin and our findings suggest that Pyridoxal phosphate prevents Gentamycin induced electrolyte imbalance.

\section{Material and Methods}

\section{Animals}

Eight to ten months old male rabbits weighing 1000 to 1500 grams were purchased locally and kept in animal house of the institution after IACUC approval. The animals were fed standard rabbit diet and water was provided ad libitum. Twelve hours light and dark cycle was maintained. Fifty four animals were divided in to three groups.

\section{Drugs}

Gentamicin sulphate and Pyridoxal-5-phosphate were purchased from Sigma-Aldrich. Fresh solution of each compound was prepared daily. The solution was stored in refrigerator for evening dosage.

\section{Experimental design}

Two groups of 18 rabbits each were administered Gentamycin and Gentamycin plus Pyridoxal phosphate intramuscularly whereas the third group was given intra-peritoneal injections of Pyridoxal phosphate alone. All the agents were given at twelve hour-interval ( 8 a.m. and 8 p.m.) for a period of fifteen days according to following dosage regimen:

- Group P was administered with Pyridoxal phosphate in a daily dose of $200 \mathrm{mg} / \mathrm{kg}$.

Corresponding author: Tahir M Khan, Department of Pharmacy Practice, College of Clinical Pharmacy, King Faisal University, Kingdom Of Saudi Arabia, E-mail: tahir.pks@gmail.com

Received February 02, 2011; Accepted January 14, 2012; Published January 20, 2012

Citation: Asif AH, Rasool ST, Khan TM (2012) Pyridoxal Phosphate a Possible Intervention to Prevent Aminoglycoside Induced Electrolyte Imbalance. J Clinic Res Bioeth 3:124. doi:10.4172/2155-9627.1000124

Copyright: (C) 2012 Asif $\mathrm{AH}$, et al. This is an open-access article distributed unde the terms of the Creative Commons Attribution License, which permits unrestricted use, distribution, and reproduction in any medium, provided the original author and source are credited. 
- Group G received Gentamycin in dose of $40 \mathrm{mg} / \mathrm{kg} / \mathrm{day}$.

- Group GP was administered with Gentamycin and Pyridoxal phosphate simultaneously in daily doses of 40 and $200 \mathrm{mg} / \mathrm{kg}$ respectively.

\section{Collection of samples}

Blood was collected from the marginal vessels of the ear at day 0 and day 16 by applying Xylene for vasodilatation. Having collected about $6 \mathrm{ml}$ of blood in a centrifuge tube, the bleeding vessel was pressed with a sterilized cotton swab till stoppage of bleeding. Serum was separated by centrifuging the collected blood at $3000 \mathrm{rpm}$ and stored at $-70^{\circ} \mathrm{C}$ for later use.

\section{Estimation of serum electrolytes}

Serum calcium concentrations were estimated with the orthocresolphthalein method with reagents manufactured by Roche Diagnostics as described earlier [19]. Commercially available reagents (Ciba-Corning, Germany) and Standard (MultiCal) were purchased locally to estimate serum potassium concentration using a flame photometer.

\section{Statistical analysis}

All the data was analyzed using statistical package for social sciences (SPSS $13^{\circ}$ ). A descriptive statistics was used to express the data as mean $\pm \mathrm{SD}$. The differences among the groups were examined by using Student's t-test. A value of p less than 0.001 was considered significant.

\section{Results}

A significant fall in serum potassium concentration was noticed on day 16 in the animals of group $\mathrm{G}(3.48 \pm 0.38 \mathrm{mEq} / \mathrm{L})$ versus group $\mathrm{P}$ $(5.17 \pm 0.48 \mathrm{mEq} / \mathrm{L})$ where Potassium levels almost remained the same as on day 0 . The potassium levels remained high $(4.78 \pm 0.5 \mathrm{mEq} / \mathrm{L})$ in group GP as compared to group $\mathrm{G}$ on day $16(\mathrm{P} \leq 0.001)$ (Figure 1$)$.

Serum calcium levels decreased significantly in group G $(7.7 \pm 0.29$ $\mathrm{mg} / \mathrm{dL})$ on day 16 of the study as compared to group P $(9.75 \pm 0.51 \mathrm{mg} /$ dL) $(\mathrm{P} \leq 0.001)$. Serum calcium levels in group $\mathrm{GP}(9.55 \pm 0.52 \mathrm{mg} /$ $\mathrm{dL}$ ) remained comparable with group $\mathrm{P}$ on day 16 of the experiment (Figure 2).

Our results suggest that Pyridoxal phosphate prevents the decline in serum electrolyte concentrations associated with Aminoglycosides.

\section{Discussion}

In our present study we examined Potassium and Calcium concentrations in the rabbit serum after injecting the animals with Gentamycin and Pyridoxal phosphate either independently or in combination. Our work shows that when given in combination, Pyridoxal phosphate prevents reduction in potassium and calcium serum levels associated with Gentamycin.

We selected daily dose of $40 \mathrm{mg}$ per kg for Gentamycin as most of the research workers preferred doses of either $40 \mathrm{mg}[20,21]$ or $60 \mathrm{mg}$ per kg per day $[22,23]$ in their experimental models. The use of similar doses is based on their similar therapeutic dose, implicated in clinical practice.

In the current study significantly lower levels of serum potassium $(\mathrm{P}<0.001)$ were observed in Gentamycin treated animals. These results are in agreement with the previous findings [15,24,25]. There

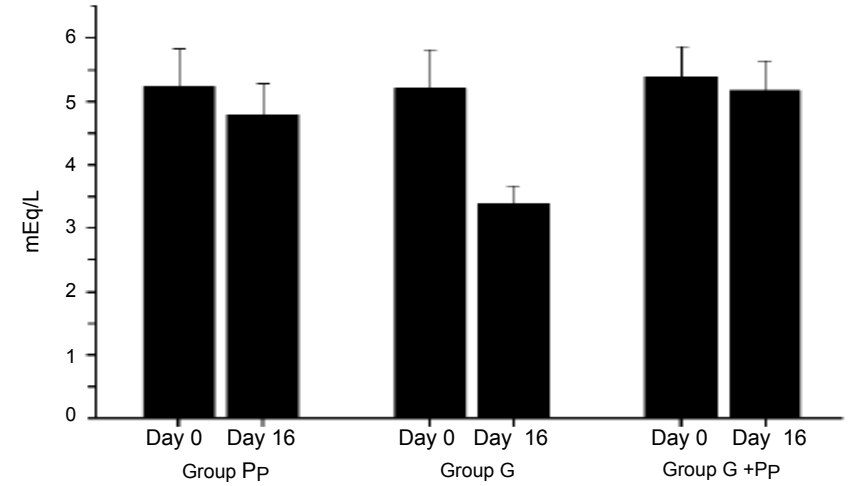

Figure 1: Change in Potassium levels among group $P, G$ and Gentamicin plus Pyridoxal phosphate (GP), during a fifteen day trial in rabbits. Serum Potassium levels decreased by $35 \%$ by day sixteen in group receiving only gentamicin while there was only $8 \%$ decrease in group receiving gentamicin along with Pyridoxal phosphate on day sixteen. The potassium levels remained high (4.78 $\pm 0.5 \mathrm{mEq} / \mathrm{L})$ in group $\mathrm{GP}$ as compared to group $\mathrm{G}$ on day $16(\mathrm{P}<0.001)$.

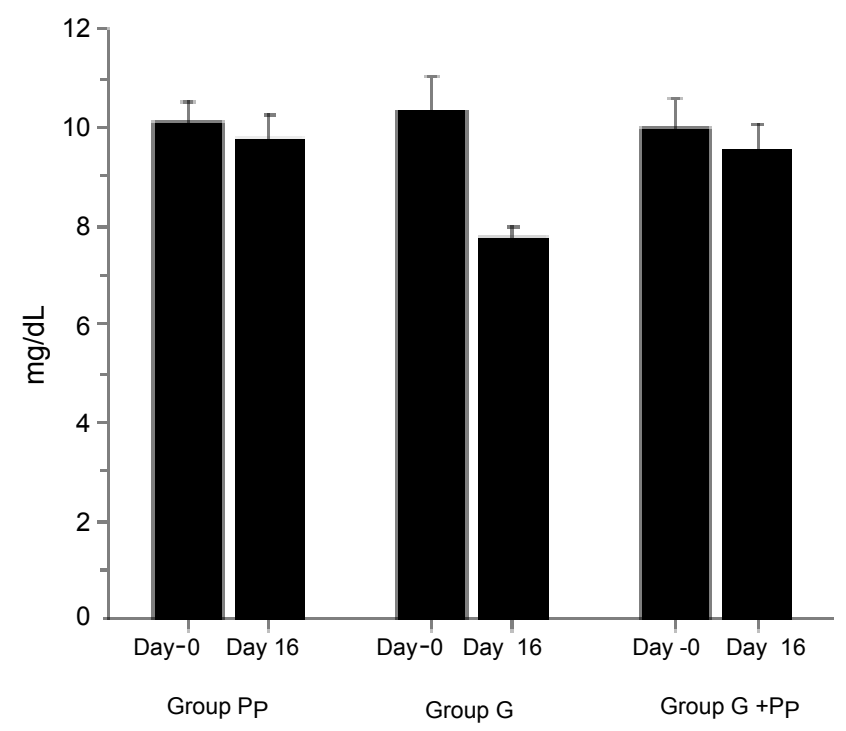

Figure 2: Change in calcium levels in groups $P, G$ and Gentamicin plus Pyridoxal phosphate (GP) during a fifteen day trial in rabbits. Serum calcium levels decreased by $25 \%$ by day sixteen in group receiving only gentamicin while there was only $4 \%$ decrease serum calcium in group receiving gentamicin along with Pyridoxal phosphate. Serum calcium levels remained high (9.55 $0.52 \mathrm{mg} / \mathrm{dL})$ in group GP as compared to group $\mathrm{G}$ on day $16(\mathrm{P}<0.001)$.

was no change seen in the animals which were co-administered with Pyridoxal phosphate, suggesting a protective role of the active form of Vit B. A significant decrease is also seen in case of calcium when aminoglycosides are administered alone, whereas there is not much change in the serum calcium levels even after fifteen days when Gentamycin was administered along with Pyridoxal phosphate.

Abnormal urinary excretion of sodium, potassium, calcium and magnesium has been described [9]. This may explain the reduction of electrolyte levels when Aminoglycosides are administered alone. However a Schiff base is formed between the amino group of aminoglycosides and the aldehyde group of Pyridoxal phosphate which decreases the nephrotoxicity of the antibiotics. Pyridoxal phosphate prevents the binding of aminoglycosides to the brush boarder 
Citation: Asif AH, Rasool ST, Khan TM (2012) Pyridoxal Phosphate a Possible Intervention to Prevent Aminoglycoside Induced Electrolyte Imbalance. J Clinic Res Bioeth 3:124. doi:10.4172/2155-9627.1000124

Page 3 of 3

membrane of the proximal tubules and this is due to the interaction of Pyridoxal phosphate and aminoglycosides outside of brush border membrane vesicles [17]. This may prevent the loss of electrolytes and hence maintaining the serum electrolyte levels.

Our study provides an important insight regarding prevention of aminoglycoside induced decrease in electrolyte levels. Further studies will help healthcare providers to decide about managing their patients in which electrolytes balance may need to be watched. We have not studied that how the Pyridoxal phosphate affects the magnesium levels when given along with aminoglycosides. This needs to be carried out in future.

\section{References}

1. Durante-Mangoni E, Grammatikos A, Utili R, Falagas ME (2009) Do we still need the aminoglycosides? Int J Antimicrob Agents 33: 201-205.

2. Hessen MT, Pitsakis PG, Levison ME (1989) Postantibiotic effect of penicillin plus gentamicin versus Enterococcus faecalis in vitro and in vivo. Antimicrob Agents Chemother 33: 608-611.

3. Karlowsky JA, Zhanel GG, Davidson RJ, Hoban DJ (1994) Postantibiotic effect in Pseudomonas aeruginosa following single and multiple aminoglycoside exposures in vitro. J Antimicrob Chemother 33: 937-947.

4. Freeman CD, Nicolau DP, Belliveau PP, Nightingale CH (1997) Once-daily dosing of aminoglycosides: review and recommendations for clinical practice. $J$ Antimicrob Chemother 39: 677-686.

5. Preston SL, Briceland LL (1995) Single daily dosing of aminoglycosides. Pharmacotherapy 15: 297-316.

6. Walker RJ, Duggin GG (1988) Drug nephrotoxicity. Annu Rev Pharmaco Toxicol 28: 331-345.

7. Prins JM, Weverling GJ, de Blok K, van Ketel RJ, Speelman P (1996) Validation and nephrotoxicity of a simplified once-daily aminoglycoside dosing schedule and guidelines for monitoring therapy. Antimicrob Agents Chemother 40: 24942499 .

8. Smith CR, Lipsky JJ, Laskin OL, Hellmann DB, Mellits ED, et al. (1980) Doubleblind comparison of the nephrotoxicity and auditory toxicity of gentamicin and tobramycin. N Engl J Med 302: 1106-1109.

9. Elliott C, Newman N, Madan A (2000) Gentamicin effects on urinary electrolyte excretion in healthy subjects. Clin Pharmacol Ther 67: 16-21.

10. Vithayasai $P$, Rojanasthien N, Punglumpoo S (1989) A case of hypomagnesemia hypocalcemia as a complication of aminoglycoside and review of the literature. J Med Assoc Thai 72: 413-416.
11. Ghiculescu RA, Kubler PA (2006) Aminoglycoside-associated Fanconi syndrome. Am J Kidney Dis 48: e89-e93.

12. Liamis G, Milionis HJ, Elisaf M (2009) A review of drug-induced hypocalcemia. J Bone Miner Metab 27: 635-642.

13. Weinberg JM (1986) The role of cell calcium overload in nephrotoxic rena tubular cell injury. Am J Kidney Dis 8: 284-291.

14. Cronin RE, Nix KL, Ferguson ER, Southern PM, Henrich WL (1982) Renal cortex ion composition and Na-K-ATPase activity in gentamicin nephrotoxicity. Am J Physiol 242: F477-F483.

15. Brinker KR, Bulger RE, Dobyan DC, Stacey TR, Southern PM, et al. (1981) Effect of potassium depletion on gentamicin nephrotoxicity. J Lab Clin Med 98: 292-301.

16. Cronin RE, Thompson JR (1991) Role of potassium in the pathogenesis of acute renal failure. Miner Electrolyte Metab 17: 100-105.

17. Kojima R, Ito M, Suzuki Y (1990) Studies on the nephrotoxicity of aminoglycoside antibiotics and protection from these effects (8): Protective effect of pyridoxal5'-phosphate against tobramycin nephrotoxicity. Jpn J Pharmacol 52: 11-21.

18. Smetana S, Khalef S, Kopolovic G, Bar-Khayim Y, Birk Y, et al. (1992) Effect of interaction between gentamicin and pyridoxal-5-phosphate on functional and metabolic parameters in kidneys of female Sprague-Dawley rats. Ren Fail 14 147-153.

19. Brown JJ, Hynes MR, Wible JH Jr (2007) Measurement of serum calcium concentration after administration of four gadolinium-based contrast agents to human volunteers. AJR Am J Roentgenol 189: 1539-1544.

20. Houghton DC, Lee D, Gilbert DN, Bennett WM (1986) Chronic gentamicin nephrotoxicity. Continued tubular injury with preserved glomerular filtration function. Am J Pathol 123: 183-194.

21. Gilbert DN, Wood CA, Kohlhepp SJ, Kohnen PW, Houghton DC, et al. (1989) Polyaspartic acid prevents experimental aminoglycoside nephrotoxicity. J Infect Dis 159: 945-953.

22. Ademuyiwa O, Ngaha EO, Ubah FO (1990) Vitamin E and selenium in gentamicin nephrotoxicity. Hum Exp Toxicol 9: 281-288.

23. Zager RA (1992) Gentamicin effects on renal ischemia/reperfusion injury. Circ Res 70: 20-28.

24. Cronin RE, Bulger RE, Southern P, Henrich WL (1980) Natural history of aminoglycoside nephrotoxicity in the dog. J Lab Clin Med 95: 463-474.

25. Thompson JR, Simonsen R, Spindler MA, Southern PM, Cronin RE (1990) Protective effect of $\mathrm{KCl}$ loading in gentamicin nephrotoxicity. Am J Kidney Dis 15: 583-591. 